\title{
SCIDiC
}

\author{
International Journal of Dentistry and Oral Science (IJDOS) \\ ISSN: 2377-8075
}

\section{Pathological Migration Of Anterior Teeth In Patients Choosing Orthodontic Treatment - A Retrospective Study}

Research Article

Ashfaq Ahmed $\mathrm{M}^{1}$, S.P.Saravana Dinesh ${ }^{2 *}$

${ }^{1}$ Saveetha Dental College and Hospitals, Saveetha Institute of Medical and Technical Sciences, Chennai - 600 077, TN, India.

${ }^{2}$ Professor and Head of Admin, Department of orthodontics and Dentofacial Orthopedics, Saveetha Dental College, Saveetha Institute of Medical and Technical Sciences, Saveetha University, 162, Poonamallee High Road, Chennai - 600077, Tamil Nadu, India.

\section{Abstract}

Pathological migration of anterior teeth is a functional and esthetic problem that may be associated with the destruction of supporting structures of the periodontal ligament. It is defined as a change in the tooth position that occurs as a result of disruption of the maintenance of the normal position of the teeth in their arch. Anterior teeth are especially prone to elongation and displacement as they are not protected by occlusal forces and have no antero-posterior contacts to inhibit tooth migration. To ensure a good clinical outcome, excellent coordination care must be taken between orthodontic and periodontal discipline. A retrospective analysis was done by analysing patient records present in saveetha dental college where patients' intraoperative photographs were checked for cross verification. Records of 7386 subjects from the hospital database were analysed. Results obtained were tabulated and statistically analysed using chi square test. Within the limits of this study pathological migration was more prevalent among the age group of $30-50$ years $(0.82 \%)$ than other age groups and the results were statistically significant $(\mathrm{p}<0.05)$. Similarly male patients $(0.76 \%)$ had higher prevalence of pathological migration when compared to female patients $(0.49 \%)$ but the results obtained were statistically insignificant $(\mathrm{p}>0.05)$. Among the 84 patients who had pathological migration in the anterior teeth region, most of the patients who belonged to the age group 30-50 years(15.48) have undergone orthodontic treatment. 10 male patients $(11.9 \%)$ and 13 female patients $(15.48 \%)$ underwent orthodontic treatment and the results were found to be statistically insignificant $(\mathrm{p}>0.05)$.

Keywords: Orthodontic Treatment; Pathological Migration; Esthetic; Periodontal Ligament; Periodontal Therapy.

\section{Introduction}

Pathological migration of anterior teeth is a functional and esthetic problem that may be associated with the destruction of supporting structures of the periodontal ligament [1]. It is defined as a change in the tooth position that occurs as a result of disruption of the maintenance of normal position of the tooth in their arch [2]. This disruption can be caused by various etiological factors such as gingivitis, occlusal factors, iatrogenic factors, oral habits like bruxism, tongue thrusting, mouth breathing, lip forces, loss of teeth without replacement, sucking habits, gingival enlargement etc. However destruction of the periodontal ligament fibres are the most relevant factor associated with pathological migration [3]. Forced orthodontic eruption of the tooth will result in sound tooth structure occlusal to the gingival margin and help preserve the junctional epithelium [4].

Although case reports have shown that repositioning of these teeth by appropriate orthodontic movement may restore the healthy and stable relationship improving the patient's Dentofacial esthetics [5]. Orthodontic treatment should be initiated after periodontal disease is brought under control [6]. Anterior teeth are especially prone to elongation and displacement as they are not protected by occlusal forces and have no antero-posterior contacts to inhibit tooth migration. To ensure a good clinical outcome, excellent coordination care must be taken between orthodontic and periodontal discipline [7]. The point of force application lies apical to the center of resistance of the maxil-

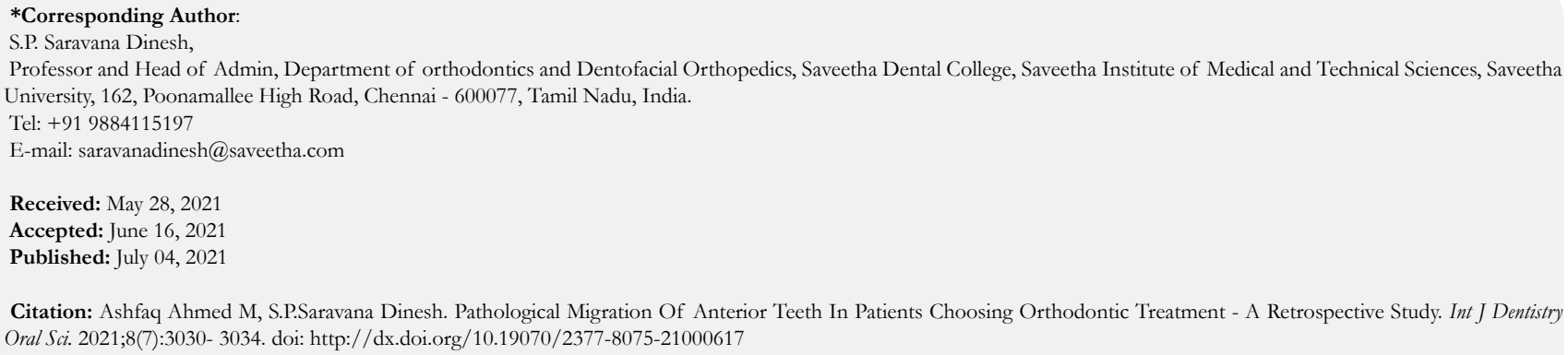

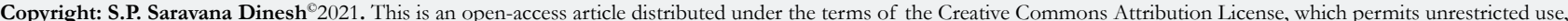
distribution and reproduction in any medium, provided the original author and source are credited. 
lary anterior teeth [8]. The force delivered from auxiliaries is commonly calibrated using Dontrix tension gauge and Correx gauge in clinical situations [9]. The cortical bone present in the mandible would receive larger stress while orthodontic forces were owing to the higher elastic modulus of the cortical bone compared with that of the spongy bone in the maxilla [10]. These interactions are mutually beneficial, allowing the diseased periodontium to be significantly improved and permitting tooth movement.

The fundamentals of orthodontic treatment is that teeth move through the alveolar bone when adequate forces are delivered [11]. Successful orthodontic management of a tooth depends on the degree of the tooth's vertical position, and the maturity of the tooth apex [12]. Indian population has been largely divided into seven ethnic groups based on their anthropometric measurements, skin colour and language. The food, dietary habits and language differ and hence prevalence of malocclusion. Chennai, the capital of Tamil Nadu in India, is a cosmopolitan city [13]. If the patient is reasonably motivated and responds well to the initial periodontal therapy, adult orthodontic treatment has a role in providing complete rehabilitation in terms of both function and appearance, with a satisfactory long-term prognosis. Dental health education, enhanced oral hygiene instructions and regular periodontal care are essential during orthodontic treatment [14]. Diagnosis of the periodontal disease can be made by tactile sense using a Williams probe, radiographically interpreting the structure of alveolar bone, periodontal ligament space, level of bone loss etc, patients with systemic diseases also show signs of pathological migration. Previously our team has a rich experience in working on various research projects across multiple disciplines The $[4,15-28]$.

Thus the aim of the study is to evaluate the percentage of patients with pathological migration of anterior teeth choosing orthodontic treatment.

\section{Materials And Methods}

A single centre retrospective study was done in an institutional setting. The ethical approval was received from the institutional ethical committee. The study involved 86000 patients in which selected patients data who had periodontitis were taken. The necessary approvals in gaining the datas were obtained from the institutional ethical committee (SDC/SIHEC/2020/DIASDATA/0619-0320). The number of people involved in the study were a guide, a reviewer and a researcher.

\section{Selection of Subjects}

All patients who had periodontitis from the time period of june 2019 to april 2020 were selected for the study $(\mathrm{N}=7386)$. All available data were taken into consideration and there was no sorting process.

\section{Data collection}

The patients' details were retrieved from the institution's patient record management software. Data regarding patients age, gender, periodontal condition and Orthodontic treatment were taken into consideration for this study. Cross verification was done with the help of photographs and radiographs. The data was manually verified, tabulated and sorted.

\section{Inclusion criteria}

All patients with pathological migration in the anterior maxillary and mandibular region were taken into account.

\section{Exclusion criteria}

Patients' records that were incomplete were removed from the study. Repetitive entries were also removed. Patients who had systemic illness, Multiple loss of teeth were also excluded from the study.

\section{Statistical analysis}

The tabulation of data was analysed using SPSS software (IBM SPSS Statistics version 23.0) The method of statistical analysis that was used in this study was Chi square test to compare two proportions. The analysis was done for age, gender, periodontal condition and Orthodontic treatment in this study.

\section{Results And Discussion}

A study by Khorshidi et al on pathological tooth migration says that the mean age of subjects with tooth migration due to periodontal pathology was 37.7 years. It was observed from the study that among the 7386 patients who had maxillary and mandibular anterior spacing, only 84 patients had periodontitis with pathological migration. 13 patients $(0.19 \%)$ belonged to the age group of $18-30$ years, 55 patients $(0.82 \%)$ belonged to $31-50$ years age group and 16 patients $(0.24 \%)$ belonged to the age group of $50-75$ years. Statistical analysis showed that the results were significant $(\mathrm{p}<0.05)$ proving association between age and pathological migration (Figure 1).

Even though this study showed a male predominance with 51 male patients $(0.76 \%)$ and $33(0.49 \%)$ female patients, the results obtained were statistically insignificant $(\mathrm{p}>0.05)$ proving that there is no association between gender and pathological migration (Figure 2) and the same study by khorshidi said that males were more prevalent to pathological migration than females, still the results were not significant [29].

Among the 84 patients who had pathological migration of anterior teeth, 6 patients who belonged to age group 18-30 years, 13 patients in age group 30-50 years and 4 patients in age group 5075 years underwent orthodontic treatment. While the remaining 61 patients $(72.62 \%)$ did not undergo orthodontic treatment. The association between the age groups that underwent Orthodontic treatment was statistically not significant $(\mathrm{p}>0.05)$ (Figure 3).

A study by Cirelli et al, a case report of a 36 year old female with a chief complaint of spacing in anterior tooth region, with a diagnosis of generalised chronic periodontitis. Patient was advised for a multidisciplinary approach with a combination of periodontal therapy, orthodontic and restorative treatment which reduced the effects of periodontal destruction and restored the tooth to the normal position [30].

Another study done by panwar et al showed comparison of GI, 
Figure 1. Bar graph represents the association between patients of different age groups and their periodontal status. $\mathrm{X}$-axis represents the age groups and Y-axis represents the total number of patients. Blue colour represents patients with healthy periodontium and green represents patients with periodontitis. Majority of the patients did not have pathological migration but among those who had it, a higher prevalence was seen in the age group of 30-50 years compared to other age groups. (Chi square test, p-value: $0.032(\mathrm{p}<0.05)$, statistically significant.

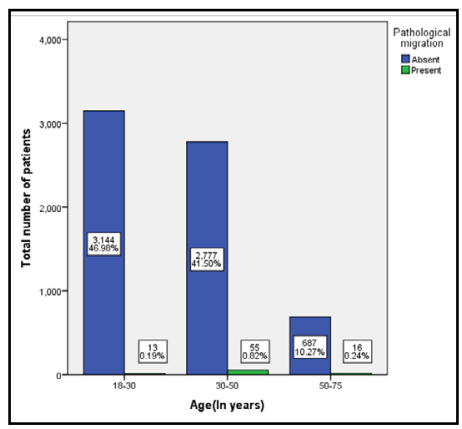

Figure 2. Bar graph represents the association between gender and the periodontal status. $\mathrm{X}$-axis denotes gender and $\mathrm{y}$ axis denotes total number of patients. Blue colour represents patients with healthy periodontium and green represents patients with periodontitis. Majority of the patients did not have pathological migration but among those who had it, a higher prevalence was seen in males when compared to females. (Chi square test, p-value: 0.607 (p>0.05), statistically NOT significant.

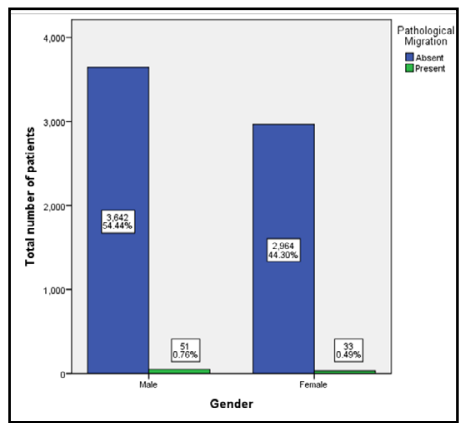

Figure 3. Bar graph represents the association between age groups and orthodontic treatment in patients with pathological migration of anteriors. $\mathrm{X}$-axis denotes age groups and $\mathrm{y}$ axis denotes total number of patients. Among the 84 patients with pathological migration, the majority did not undergo orthodontic treatment(green). Whereas, 13 patients in the age group 30-50 years, 6 in the age group 18-30 years and 4 in the group 50-75 years have undergone orthodontic treatment(blue). (Chi square test, $\mathrm{p}$-value: $0.254(\mathrm{p}>0.05)$, statistically NOT significant.

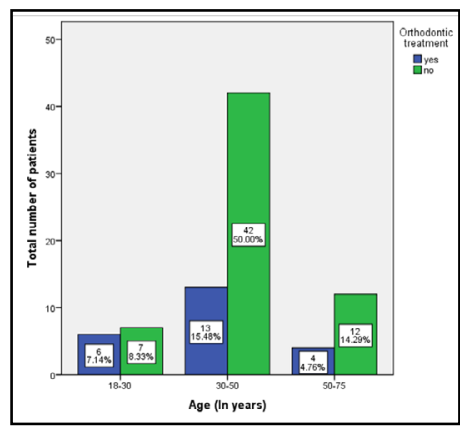

Figure 4. Bar graph represents the association between gender distribution and orthodontic treatment in patients with pathological migration of anteriors. $\mathrm{X}$-axis denotes gender and $\mathrm{y}$ axis denotes total number of patients. Majority of the patients did not undergo orthodontic treatment(green). Whereas among the 84 patients, 13 female patients have undergone orthodontic treatment(blue) compared to males. (Chi square test, p-value: 0.629 ( $\mathrm{p}>0.05$ ), statistically NOT significant.

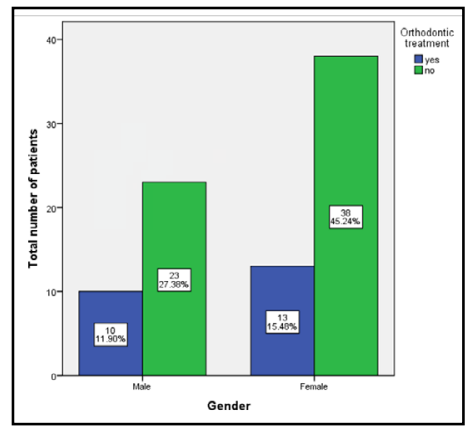


PDI and DAI before and after completion of Orthodontic treatment showed statistically significant differences, indicating the relevance of combined Orthodontic-Periodontic treatment in periodontally compromised dentition $(\mathrm{P}<0.01)[31]$.

It was also observed from the study that among the 84 patients who had pathological migration in anterior teeth region, 10 male patients $(11.9 \%)$ and 13 female patients $(15.48 \%)$ have undergone orthodontic treatment but the results are found to be statistically not significant $(\mathrm{p}>0.05)$ (Figure 4).

In this study 46 patients who had pathological migration could not be referred for Orthodontic treatment as the periodontal disease was moderate to severe. While 38 patients were advised Orthodontic treatment, 15 patients did not take it up. The reasons for this decision could be any of the following such as, low socio -economic status, anxiety about the effects of the treatment, long duration of the treatment or lack of interest. Some of the limitations of this study are that the study sample was predominantly south indian population and it is unicentered with an inadequate sample size.

Adjunctive orthodontic treatment of pathologic tooth migration has greater effects in subjects with periodontitis. Orthodontic treatment is no longer a contraindication in the therapy of severe adult periodontal disease or in the maintenance of a healthy periodontium after orthodontic treatment. Prevention of tooth migration can be made by eliminating the causative factors which are crucial for a successful orthodontic treatment and pathologically migrated teeth return to their normal position after the etiological factor is eliminated [32]. A patient judges the outcome of an orthodontic treatment by assessing the final improvement in facial esthetics [33]. Neglect of oral hygiene can lead to pathologic tooth migration which in severe cases may lead to loss of tooth which brings esthetic concerns to the patient and lowers their self esteem. Gaumet et al reported the outcomes of patients with anterior diastema due to periodontitis who underwent nonsurgical and surgical periodontal interventions and reported a complete closure of diastema in $51.5 \%$ of patients, while the remaining subjects exhibited various degrees of repositioning [34].

The results of the study can be used as a baseline data for future studies in improving the quality of patients life. The idea for this study stemmed from the current interest in our community. Clinicians should be able to diagnose pathologic tooth migration and address it to the patients. If minor pathologic tooth migration appears to be the result of periodontitis, thorough scaling and root planning should be done as a prophylactic treatment which may reverse it completely. If the migration fails to resolve, periodontal surgery as well as orthodontic and prosthetic measures should be advised to prevent the loss of tooth. Clinicians should stress the importance of regular maintenance of oral hygiene and regular dental checkup every 3 months, especially in patients with a history of periodontitis. Our institution is passionate about high quality evidence based research and has excelled in various fields [35-45].

\section{Conclusion}

Within the limits of this study pathological migration was more prevalent among the age group of 30-50 years in which males were more commonly affected. More than $50 \%$ of the patients affected with pathological migration could not undergo Orthodontic treatment due to the severity of the periodontal disease that included increased alveolar bone loss and increased mobility of teeth. Proper patient education on oral hygiene care should be able to eliminate the trivial excuses that patients cling on to avoid conservative Orthodontic treatment. It may help if the adverse effects of pathological migration are very clearly discussed with patients with periodontitis in its early stages to prevent the loss of teeth and preserve the periodontium.

\section{Acknowledgement}

The authors would like to thank Saveetha Dental College and Hospitals for providing the platform to conduct the study.

\section{References}

[1]. Brunsvold MA. Pathologic tooth migration. J. Periodontol. 2005 Jun;76(6):859-66.

[2]. Southard TE, Behrents RG, Tolley EA. The anterior component of occlusal force. Part 1. Measurement and distribution. Am J Orthod Dentofacial Orthop. 1989 Dec;96(6):493-500.Pubmed PMID: 2589259.

[3]. Guilbert PN, Rozanes SD, Tecucianu JF. Periodontal and prosthodontic treatment for patients with advanced periodontal disease. Dent Clin North Am. 1988 Apr 1;32(2):331-54.

[4]. Felicita AS. Orthodontic extrusion of Ellis Class VIII fracture of maxillary lateral incisor - The sling shot method. Saudi Dent J. 2018 Jul;30(3):265269.Pubmed PMID: 29942113.

[5]. Jäger A, Hornecker E, Mausberg R. Periodontal-orthodontic treatment possibilities for migrated front teeth. Possibilities and limits of orthodontic therapy. ZWR. 1990 Sep 1;99(9):722-4.

[6]. Re S, Corrente G, Abundo R, Cardaropoli D. Orthodontic treatment in periodontally compromised patients: 12-year report. Int J Periodontics Restorative Dent. 2000 Feb;20(1):31-9.Pubmed PMID: 11203546.

[7]. Melsen B, Agerbaek N, Markenstam G. Intrusion of incisors in adult patients with marginal bone loss. Am J Orthod Dentofacial Orthop. 1989 Sep 1;96(3):232-41.

[8]. Felicita AS. Quantification of intrusive/retraction force and moment generated during en-masse retraction of maxillary anterior teeth using mini-implants: A conceptual approach. Dental Press J Orthod. 2017 SepOct;22(5):47-55.Pubmed PMID: 29160344.

[9]. Dinesh SP, Arun AV, Sundari KK, Samantha C, Ambika K. An indigenously designed apparatus for measuring orthodontic force. J Clin Diagn Res. 2013 Nov;7(11):2623-6.Pubmed PMID: 24392423.

[10]. Sivamurthy G, Sundari S. Stress distribution patterns at mini-implant site during retraction and intrusion--a three-dimensional finite element study. Prog Orthod. 2016;17:4.Pubmed PMID: 26780464.

[11]. Krishnan S, Pandian S, Kumar S A. Effect of bisphosphonates on orthodontic tooth movement-an update. J Clin Diagn Res. 2015 Apr;9(4):ZE01-5. Pubmed PMID: 26023659.

[12]. Felicita AS. Orthodontic management of a dilacerated central incisor and partially impacted canine with unilateral extraction - A case report. Saudi Dent J. 2017 Oct;29(4):185-193.Pubmed PMID: 29033530.

[13]. Felicita AS, Chandrasekar S, Shanthasundari KK. Determination of craniofacial relation among the subethnic Indian population: a modified approach - (Sagittal relation). Indian J Dent Res. 2012 May-Jun;23(3):305-12. Pubmed PMID: 23059564.

[14]. Ajay M, Negi KS, Saroj T, Kanwarjeet AS. A successfully treated case of severe periodontitis using interdisciplinary approach: Report of a case. J Indian Soc Periodontol. 2016 Jan;20(1):95-7.

[15]. Hafeez N. Accessory foramen in the middle cranial fossa. Res J Pharm Technol. 2016;9(11):1880-2.

[16]. Krishnan RP, Ramani P, Sherlin HJ, Sukumaran G, Ramasubramanian A, Jayaraj G, et al. Surgical Specimen Handover from Operation Theater to Laboratory: A Survey. Ann Maxillofac Surg. 2018 Jul-Dec;8(2):234-238. Pubmed PMID: 30693238.

[17]. Somasundaram S, Ravi K, Rajapandian K, Gurunathan D. Fluoride Content of Bottled Drinking Water in Chennai, Tamilnadu. J Clin Diagn Res. 2015 Oct;9(10):ZC32-4.Pubmed PMID: 26557612.

[18]. Kumar S, Rahman R. Knowledge, awareness, and practices regarding biomedical waste management among undergraduate dental students. Asian J Pharm Clin Res. 2017;10(8):341. 
[19]. Gurunathan D, Shanmugaavel AK. Dental neglect among children in Chennai. J Indian Soc Pedod Prev Dent. 2016 Oct 1;34(4):364.

[20]. Sneha S. Knowledge and awareness regarding antibiotic prophylaxis for infective endocarditis among undergraduate dental students. Asian J Pharm Clin Res. 2016 Oct 1:154-9.

[21]. Dhinesh B, Lalvani JI, Parthasarathy M, Annamalai K. An assessment on performance, emission and combustion characteristics of single cylinder diesel engine powered by Cymbopogon flexuosus biofuel. Energy Convers Manage. 2016 Jun 1;117:466-74.

[22]. Choudhari S, Thenmozhi MS. Occurrence and Importance of Posterior Condylar Foramen. Res J Pharm Technol. 2016;9(8):11-43.

[23]. Paramasivam A, Vijayashree Priyadharsini J, Raghunandhakumar S. N6adenosine methylation (m6A): a promising new molecular target in hypertension and cardiovascular diseases. Hypertens Res. 2020 Feb;43(2):153154.Pubmed PMID: 31578458.

[24]. Wu F, Zhu J, Li G, Wang J, Veeraraghavan VP, Krishna Mohan S, et al. Biologically synthesized green gold nanoparticles from Siberian ginseng induce growth-inhibitory effect on melanoma cells (B16). Artif Cells Nanomed Biotechnol. 2019 Dec;47(1):3297-3305.Pubmed PMID: 31379212.

[25]. Palati S, Ramani P, Shrelin HJ, Sukumaran G, Ramasubramanian A, Don $\mathrm{KR}$, et al. Knowledge, Attitude and practice survey on the perspective of oral lesions and dental health in geriatric patients residing in old age homes. Indian J Dent Res. 2020 Jan-Feb;31(1):22-25.Pubmed PMID: 32246676.

[26]. Saravanan M, Arokiyaraj S, Lakshmi T, Pugazhendhi A. Synthesis of silver nanoparticles from Phenerochaete chrysosporium (MTCC-787) and their antibacterial activity against human pathogenic bacteria. Microb Pathog. 2018 Apr;117:68-72.Pubmed PMID: 29427709.

[27]. Govindaraju L, Gurunathan D. Effectiveness of Chewable Tooth Brush in Children-A Prospective Clinical Study. J Clin Diagn Res. 2017 Mar;11(3):ZC31-ZC34.Pubmed PMID: 28511505.

[28]. Vijayakumar Jain S, Muthusekhar MR, Baig MF, Senthilnathan P, Loganathan S, Abdul Wahab PU, et al. Evaluation of Three-Dimensional Changes in Pharyngeal Airway Following Isolated Lefort One Osteotomy for the Correction of Vertical Maxillary Excess: A Prospective Study. J Maxillofac Oral Surg. 2019 Mar;18(1):139-146.Pubmed PMID: 30728705.

[29]. Khorshidi H, Moaddeli MR, Golkari A, Heidari H, Raoofi S. The prevalence of pathologic tooth migration with respect to the severity of periodontitis. J Int Soc Prev Community Dent. 2016 Aug;6(Suppl 2):S122.

[30]. Cirelli JA, Cirelli CC, Holzhausen M, Martins LP, Brandão CH. Combined periodontal, orthodontic, and restorative treatment of pathologic migration of anterior teeth: a case report. Int J Periodontics Restorative Dent. 2006 Oct 1;26(5):501-6.

[31]. Panwar M, Jayan B, Arora V, Singh S. Orthodontic management of dentition in patients with periodontally compromised dentition. J Indian Soc Periodontol. 2014 Mar;18(2):200-4

[32]. Brunsvold MA, Zammit KW, Dongari AI. Spontaneous correction of pathologic migration following periodontal therapy. Int J Periodontics Restorative Dent. 1997 Apr 1;17(2):182-9.
[33]. Pandian KS, Krishnan S, Kumar SA. Angular photogrammetric analysis of the soft-tissue facial profile of Indian adults. Indian J. Dent. Res. $2018 \mathrm{Mar}$ $1 ; 29(2): 137$.

[34]. Gaumet PE, Brunsvold MI, McMahan CA. Spontaneous repositioning of pathologically migrated teeth. J. Periodontol. 1999 Oct;70(10):1177-84.

[35]. Vijayashree Priyadharsini J. In silico validation of the non-antibiotic drugs acetaminophen and ibuprofen as antibacterial agents against red complex pathogens. J Periodontol. 2019 Dec;90(12):1441-1448.Pubmed PMID: 31257588.

[36]. Pc J, Marimuthu T, Devadoss P, Kumar SM. Prevalence and measurement of anterior loop of the mandibular canal using CBCT: A cross sectional study. Clin Implant Dent Relat Res. 2018 Apr 6;20(4):531-4.

[37]. Ramesh A, Varghese S, Jayakumar ND, Malaiappan S. Comparative estimation of sulfiredoxin levels between chronic periodontitis and healthy patients - A case-control study. J Periodontol. 2018 Oct;89(10):1241-1248.Pubmed PMID: 30044495.

[38]. Ramadurai N, Gurunathan D, Samuel AV, Subramanian E, Rodrigues SJ. Effectiveness of $2 \%$ Articaine as an anesthetic agent in children: randomized controlled trial. Clin Oral Investig. 2019 Sep;23(9):3543-50.

[39]. Sridharan G, Ramani P, Patankar S, Vijayaraghavan R. Evaluation of salivary metabolomics in oral leukoplakia and oral squamous cell carcinoma. J. Oral Pathol. Med. 2019 Apr;48(4):299-306.

[40]. Ezhilarasan D, Apoorva VS, Ashok Vardhan N. Syzygium cumini extract induced reactive oxygen species-mediated apoptosis in human oral squamous carcinoma cells. J Oral Pathol Med. 2019 Feb;48(2):115-121.Pubmed PMID: 30451321.

[41]. Mathew MG, Samuel SR, Soni AJ, Roopa KB. Evaluation of adhesion of Streptococcus mutans, plaque accumulation on zirconia and stainless steel crowns, and surrounding gingival inflammation in primary molars: randomized controlled trial. Clin Oral Investig. 2020 Sep;24(9):1-6.Pubmed PMID: 31955271

[42]. Samuel SR. Can 5-year-olds sensibly self-report the impact of developmental enamel defects on their quality of life? Int J Paediatr Dent. 2021 Mar;31(2):285-286.Pubmed PMID: 32416620.

[43]. R H, Ramani P, Ramanathan A, R JM, S G, Ramasubramanian A, et al. CYP2 C9 polymorphism among patients with oral squamous cell carcinoma and its role in altering the metabolism of benzo[a]pyrene. Oral Surg Oral Med Oral Pathol Oral Radiol. 2020 Sep;130(3):306-312.Pubmed PMID: 32773350.

[44]. Chandrasekar R, Chandrasekhar S, Sundari KKS, Ravi P. Development and validation of a formula for objective assessment of cervical vertebral bone age. Prog Orthod. 2020 Oct 12;21(1):38.Pubmed PMID: 33043408.

[45]. Vijayashree Priyadharsini J, Smiline Girija AS, Paramasivam A. In silico analysis of virulence genes in an emerging dental pathogen A. baumannii and related species. Arch Oral Biol. 2018 Oct;94:93-98.Pubmed PMID: 30015217. 